\title{
Physicochemical and sensory analysis of instant cereal beverage incorporated with corncob powder
}

\author{
${ }^{1}$ Lee, C.M., ${ }^{2}$ Chan, Y.L., ${ }^{2}$ Gan, Y.L., ${ }^{1}$ Tang, T.K., ${ }^{3}$ Tan C.P. and ${ }^{1,2 *}$ Lai, O.M. \\ ${ }^{1}$ Institute of Bioscience, Universiti Putra Malaysia, Serdang, Selangor, Malaysia \\ ${ }^{2}$ Department of Bioprocess Technology, Faculty of Biotechnology and Biomolecular Sciences, Universiti \\ Putra Malaysia, Serdang, Selangor, Malaysia \\ ${ }^{3}$ Department of Food Technology, Faculty of Food Science and Technology, Universiti Putra Malaysia, \\ Serdang, Selangor, Malaysia
}

\author{
Article history: \\ Received: 10 June 2018 \\ Received in revised form: 6 \\ July 2018 \\ Accepted: 9 July 2018 \\ Available Online: 19 July \\ 2018
}

Keywords:

Physicochemical,

Sensory,

Corncob,

Instant cereal beverage

DOI:

https://doi.org/10.26656/fr.2017.2(5).203

\begin{abstract}
The primary objectives of this study were to process corncob into corncob powder (CCP) and to apply CCP in the formulation of instant cereal beverage (ICB) in order to produce high fibre ICB, and to investigate the physicochemical and sensory properties of the corncob-based instant cereal beverage. Corncobs were sourced and washed thoroughly before drying and grinding into CCP. CCP was then imparted into ICB formulation in three different ratios $(10,20$ and $30 \% \mathrm{w} / \mathrm{w})$ to partially substitute corn flour in the formulation. All four ICB samples including the commercial counterpart were analysed for their physicochemical and sensory properties. The incorporation of CCP has affected the viscosity, colour and sensory attributes significantly of the produced ICB. Higher contents of CCP in the formulation was found to be responsible for less viscous and browner effect compared to the commercial ICB samples. Formulation of ICB incorporated with $30 \% \mathrm{w} / \mathrm{w}$ CCP had the highest mean scores $(6.00, \mathrm{p}<0.05)$ of overall acceptability among all the other formulations and it was comparable to the commercial ICB in the current market.
\end{abstract}

\section{Introduction}

Maize is among the most versatile emerging cereal crops, having far-ranging adaptability under various climatic conditions. Besides rice and wheat, maize becomes the third most vital cereal crops. Maize which is also known as corn is one of the most common and widely planted cereal crops around the globe (Ramessar et al., 2008). In Malaysia, corn is one of the favourite cereals which is extensively being planted. According to FAO (2016), the total amount of corn production in Malaysia alone increased to 86,643 tonnes in 2014 from 47,602 tonnes in 2010. Corn provides a secure market in this country (Wong, 1993). Other than its food application, corn and its other plant parts are also been utilized in agricultural and health fields (Voca et al., 2009; Naqvi et al., 2011). However, corn-processing industries have also generated a large amount of left unused CC. A huge amount of CC was produced considering the weight proportion between corn kernels and CC may reach 100:18. Although there is no report on the yield of CC in Malaysia, it is estimated that there would be 9531 tonnes of $\mathrm{CC}$ being produced in Malaysia in 2014 by referring to the weight ratio of corn kernels to $\mathrm{CC}$ mentioned earlier.

Food products which are boosted with health benefits are getting progressively popular lately. In the industry of processed food industry, one of the interesting research area is "Functional Foods". Definition of functional foods (FF) has been proposed by few international health organizations such as International Life Sciences Institute (ILSI) and International Food Information Council (IFIC) and professionals as food with the extra function by including new ingredients or higher amount of the current ingredients which give benign physiological or health. Issues related to health such as personal wellbeing and FF will be an interesting subject as the growing population is hoping longevity. FF products that improve health and help in body slimming will be favoured by consumers. A number of evidence has proven that diets with high fibre contents particularly those consisting cereal fibre provide health advantages in lowering the chance of chronic diseases (Katina and Cauvain, 2003). Therefore, high fibre food products 
(HFFP) will be in demand and unquestionably sought after. Traditionally, the inevitable worsening of quality in terms of texture and flavour of HFFP will occur normally after a significant amount of fibre is being introduced into food products (Katina and Cauvain, 2003). It is a challenge for the food industry to formulate food products that contain high dietary fibre (DF) content. For the recent decades, a huge market for products rich in fibre has been greatly developed due to the immense interest in food which is rich in DF. Cereals, tubers, fruits, algae, and vegetables, which are all known by its high content of DF with low digestibility and low caloric content has been the focus of many research (Alfredo et al., 2009). However, not many studies on the application of $\mathrm{CC}$ in food production especially the production of instant beverage had been carried out. If the important fibre which is freely available in CC is ignored, this will cause a heavy loss in food industries especially when food security is one of the major issues in the world nowadays.

The presence of the latest fibre sources as well as the processing techniques that used to improve their functionality have provided new potential for formulating fibre enhanced products. Besides that, they have also broadened the usages of fibres in the food industry and developed new textures in a wide range of applications (Rosell et al., 2009). Few of the by-products of food processing exemplified by apples, citrus fruits, and Brassica vegetables have been utilized in the production of DF (Chantaro et al., 2008). The products are then incorporated into staple food including buns and noodles, baked products, dairy products, FF and beverage to improve the properties of the final products. There are also reports on the utilization of wheat bran, oat bran and rice bran as sources of DF content in bakery products such as bread (Laurikainen et al., 1998).

One of the food products that satisfy the need of customers who demand convenience and simplicity in food preparations is ICB powders. ICB is favoured by most people because they have a long shelf life as well. Moreover, it is also considered healthy food for all age groups and genders of customers. Few agricultural crops products such as corn and soybean have been successfully processed into instant beverage powders that can be prepared in short amount of time by dissolving in hot water (Charunuch et al., 2008).

For ICB powder production, most of the ingredients utilized come in the form of liquid or high viscosity liquids. These materials need to be heated and dried by means of a spray drier (Holsinger et al., 1974; Guy and Vettel, 1975; King, 1985). However, different methods can be used if the main raw material is cereal and in powder form. The two most applied processing methods are drum drying method (Anderson et al., 1971) and extrusion cooking method which the former uses high temperature and pressure roller machine and the latter use single screw extruder (Bookwalter et al., 1971).

Drum drying method produces ICB powders by cooking and drying the mixture of ingredients by using the high temperature and pressure roller machines. This process will produce a flaked product which will then be grounded and sifted with desirable mesh size. After that, other food materials such as milk powder will be added to enhance the flavour and nutrition of the beverage (Charunuch et al., 2008).

The primary objectives of this study were to produce corncob powder (CCP) from corncob (CC) and incorporate CCP into the ICB formulation in order to develop ICB powder. The physicochemical and sensory properties of the ICB which was incorporated with CCP were also investigated and discussed as well.

\section{Materials and methods}

\subsection{Materials}

Raw CC was collected from Nelson's Franchise Sdn. Bhd. which owned a corn plantation in Ipoh district, Perak state of Malaysia. Other materials which were required for the preparation and production of ICB were bought from a local bakery shop and local market in Sri Serdang, Selangor. Chosen commercial counterpart which was Nestum Grains and More 3 in 1 (NGM) (Nestlé Bhd., Malaysia) was purchased from the local market as well. Materials needed for sensory evaluation test of ICB were sourced from the local market in Sri Serdang, Selangor.

\subsection{Preparation of corncob powder (CCP)}

Collected CC was cleaned with distilled water and grounded into coarse powdery form with a coconut grinder. After that, $\mathrm{CC}$ was dried in an oven (Memmert, Germany) for $36 \mathrm{hrs}$ at $60^{\circ} \mathrm{C}$. Dried CC was then ground into finer powdery particles using a heavy-duty blender (Waring Commercial, USA) for 5 mins. After that, it was fractionated into fine and coarse powder fractions with an 80 microns sieve. The fine CCP obtained was sealed in zip-lock plastic bags and stored at $4{ }^{\circ} \mathrm{C}$ prior to any analysis and utilization.

\subsection{Proximate composition analysis}

Proximate compositions analysis was done on the commercial corn flour (CF) and CCP by using the official AOAC methods (2002). The parameters that were analysed were moisture, ash, fat, crude fibre, protein, carbohydrate (by difference) and calorie content. 
The results were displayed as $\mathrm{g} / 100 \mathrm{~g}$ of dry matter.

\subsection{Preparation of instant cereal beverage (ICB)}

Three batches of ICB flakes formulation each with various $\mathrm{CCP}$ content ranging from $10-30 \%$ were prepared with the amounts of ingredients stated in Table 1. The formulations were modified based on the corn flakes formulations (Al-Okbi et al., 2014). All the ingredients were weighed and added into a mixing bowl. Then, $400 \mathrm{~mL}$ of distilled water was poured into the bowl. The ingredients inside the bowl were mixed thoroughly until a smooth slurry was formed. Then the slurry was dried with a double drum dryer (Simon Ltd. Nip Feed Test Machine, Model 4766, Nottingham, UK). The drum dryer had a volume capacity of 19L with 30 $\mathrm{cm}$ diameter x $20 \mathrm{~cm}$ length of the drum size. The slurry was cooked and dried under the condition of $1 \mathrm{rpm}$ of the drum rolling speed and with a steam pressure of 2 bar. The gap of the drums was set at $0.1 \mathrm{~mm}$ (Chia and Chong, 2015). $200 \mathrm{~g}$ of the slurry was cooked and dried until flakes was produced and scrapped by the blades on the drums. The whole process took about 6-8 mins. After the instant cereal flakes was collected, it was grounded into powder form using a heavy-duty blender (Waring Commercial, USA). Subsequently, $600 \mathrm{~g}$ of the ground cereal beverage powder was mixed with $400 \mathrm{~g}$ of milk powder to improve the palatability and nutritional values of ICB. Then it was packed individually with each weight of $28 \mathrm{~g}$.

Table 1. Composition of ICB flakes formulas

\begin{tabular}{lccc}
\hline \multirow{2}{*}{ Ingredients } & \multicolumn{3}{c}{ Different } \\
\cline { 2 - 4 } & ICB10 & ICB20 & ICB30 \\
\hline CF $(\mathrm{g})$ & 800 & 700 & 600 \\
$\mathrm{CCP}(\mathrm{g})$ & 100 & 200 & 300 \\
Sugar $(\mathrm{g})$ & 70 & 70 & 70 \\
Salt $(\mathrm{g})$ & 30 & 30 & 30 \\
Water $(\mathrm{mL})$ & 400 & 400 & 400 \\
\hline
\end{tabular}

ICB10: instant cereal beverage powder substituted with $10 \%$ corncob powder, ICB20: instant cereal beverage powder substituted with $20 \%$ corncob beverage, ICB30: instant cereal beverage powder substituted with $30 \%$ corncob powder.

\subsection{Viscosity measurements}

ICB10, ICB20, ICB30 and the commercial counterparts: NGM (Nestlé Bhd., Malaysia) were prepared by mixing $28 \mathrm{~g}$ of each sample with $120 \mathrm{~mL}$ of hot water $\left(90^{\circ} \mathrm{C}\right)$. Then, they were stirred thoroughly to avoid any lump formation as this would affect the measurements of viscosity. Then their viscosity (mpa.s) were measured with RheolabQC rotational rheometer equipped with cylindrical spindle (Anton Paar, Germany) at $37^{\circ} \mathrm{C}$ with different shear rates (1/s) at 100 , 1000 and 1500. Shear rate of $100 \mathrm{~s}^{-1}, 1000 \mathrm{~s}^{-1}$ and $1500 \mathrm{~s}^{-}$ ${ }^{1}$ were chosen to measure the viscosity as these shear rates represent the common process of chewing, handstirring and machinery-mixing, respectively. The viscosity analysis was done at the body temperature $\left(37^{\circ}\right.$ C) to understand viscosity of ICBs better when they were swallowed down into the oesophagus.

\subsection{Colour measurements}

A HunterLab LabScan XE Spectrophotometer with D65 light source (Hunter Associates Laboratory, Inc., Reston, VA) was used to analyze the colour of ICBs for the values of $\mathrm{L}^{*}$ (Lightness), $\mathrm{a}^{*}$ (Redness) and $\mathrm{b}^{*}$ (Yellowness). A standardized kit was used to standardize the system with RSEX mode (Mode for shiny and glossy solid or semi-solid samples) before samples analysis. Then, $50 \mathrm{~mL}$ of liquid samples were slowly poured into the specialized optical glass cell with $10 \mathrm{~mm}$ thickness. The optical glass cell was then put into the spectrophotometer for obtaining the colour values.

\subsection{Sensory evaluation}

An acceptance test was conducted on the sensory evaluation of ICB10, ICB20, ICB30 and NGM (Nestlé Bhd., Malaysia) in terms of colour, aroma, taste, viscosity, grittiness and overall acceptance. Thirty untrained panelists were invited to participate in this evaluation. All of them were undergraduate and postgraduate students from Universiti Putra Malaysia (UPM) with ages ranging from 18 to 26 . Panelists must possess good health and dentition, and non-smokers. The evaluation was conducted in Food Sensory Laboratory at Faculty of Food Science and Technology in UPM under ambient temperature and fluorescent light. Tissue, plain water, and spit cup were given to all the panelists on a tray. Before sensory evaluation sessions, all the panelists were briefed for the definition of descriptive terms. Then, each of the samples was served to them in paper cups with 4-digit random numbers labeled to them. Panelists were required to rinse their mouths after each sample evaluation before went on for the next sample. Panelists then would have to answer a sensory evaluation form which had a 9-point hedonic scale for each sample for the attribute mentioned. The evaluation was based on their degree of like (scale of 1-9) where $1=$ dislike extremely and $9=$ like extremely. Samples with the mean scores of more than 5.00 for overall acceptability were considered as acceptable.

\subsection{Statistical analysis}

Data were analysed with SPSS 18.0 (SPSS Inc., Chicago, USA) based on independent t-test or one-way ANOVA procedure. Results were displayed as mean \pm standard deviation. All analysis was conducted in triplicate $(n=3)$. The significant level was adjusted at $\mathrm{p}<0.05$. 


\section{Results and discussion}

\subsection{Proximate composition}

The formulation and production of ICB involved a significant amount of $\mathrm{CF}$, and part of the $\mathrm{CF}$ in the ICB formulation was replaced with $\mathrm{CCP}$, therefore $\mathrm{CF}$ was selected to be the counterpart of CCP in order to compare their nutritional contents. From the obtained results, all the proximate parameters had significant differences $(p<0.05)$ between CF and CCP over $100 \mathrm{~g}$ of dry matter. CF had significantly lower contents of ash $(1.62 \mathrm{~g})$, moisture $(8.42 \mathrm{~g})$, crude fat $(1.20 \mathrm{~g})$ and crude fibre $(1.33 \mathrm{~g})$ compared to CCP (ash content: $1.92 \mathrm{~g}$, moisture content: $11.38 \mathrm{~g}$, crude fat content: $1.38 \mathrm{~g}$ and crude fibre content: $38.52 \mathrm{~g}$, respectively). On the other hand, the crude protein $(9.73 \mathrm{~g})$, carbohydrate $(77.7 \mathrm{~g})$ and calorie content $(360.52 \mathrm{Kcal})$ of $\mathrm{CF}$ were significantly higher than CCP (crude protein content: $3.12 \mathrm{~g}$, carbohydrate content: $43.68 \mathrm{~g}$ and calorie content: $199.62 \mathrm{Kcal})$. From the result obtained, several obvious differences in terms of nutritional contents among $\mathrm{CF}$ and $\mathrm{CCP}$ were noticed. This could be largely due to different parts of the plant that were used to process into $\mathrm{CF}$ and CCP. CF was processed from the endosperm of corn kernels that had a high content of starch while CCP was processed from corncob which consisted of insoluble fibre mainly (Kuan et al., 2011). Thus, CCP had the edge over CF to be included in cereal products such as cereal beverage and cereal flakes to boost their fibre content due to the high fibre content in CCP. Furthermore, low caloric content and high crude fibre content of CCP also gave rise to chances of producing low-calorie food products with a noticeable sense of satiety to consumers due to its great content of insoluble fibre. Food products that included ingredients which had a good amount of cellulose or insoluble fibre contents were found to be effective in treating various diseases related to alimentary tract such as duodenal and gastric ulcers, digestive tract diverticulosis, constipation, hemorrhoids and colon cancer (Hasik et al., 1997; Suter, 2005). Cholic acids and cholesterol in the alimentary tract could be bound with insoluble fibre and then excreted out from the body via feces. Subsequently, a lower level of blood cholesterol was achieved (Ebihara and Nakamoto, 2001).

\subsection{Viscosity measurements}

"Mouthfeel" was described as the rate of flow of beverages into the mouth and down the oesophagus when swallowed, under the force putting on these cavities. The flow rate of a beverage under certain applied force or viscosity was related to and recognized to be the "mouthfeel" parameter. So, the viscosity is a vital physicochemical characteristic of a beverage food product. Viscosities of ICB samples with its commercial counterpart NGM is tabulated in Table 2. Shear rate of $100 \mathrm{~s}^{-1}, 1000 \mathrm{~s}^{-1}$, and $1500 \mathrm{~s}^{-1}$ were chosen to measure the viscosity as these shear rates represent the common process of chewing, hand-stirring, and machinerymixing, respectively. The viscosity analysis was done at the body temperature $\left(37^{\circ} \mathrm{C}\right)$ to understand viscosity of ICBs better when they were swallowed down into the oesophagus. By referring to Table 5.3, the viscosity of ICBs was significantly different $(p<0.05)$ with each other. ICB10 was significantly $(\mathrm{p}<0.05)$ the most viscous sample among all the tested samples. This was largely caused by the high corn flour content in the formulation. ICB30 had significantly the least viscosity values $(\mathrm{p}<0.05)$ compared to ICB10 and ICB20 at 3 different shear rates. However, ICB30 was significantly $(p<0.05)$ more viscous than its commercial counterparts (NGM) at all the shear rates tested. This was hugely due to the different type and content of thickening agent used in both formulations. Other than being the source of energy in ICBs, corn starch was applied as thickener as well, whereas maltodextrin was used as thickener and filler in NGM. At shear rate of $100 \mathrm{~s}^{-1}$, ICB30 had the nearest values of viscosity to NGM even though the difference was significant $(p<0.05)$. At shear rates of $1000 \mathrm{~s}^{-1}$ and $1500 \mathrm{~s}^{-1}$, ICB20 had the nearest viscosity with NGM. With the increasing amount of CCP in the formulation, ICBs tended to be less viscous. This was due to the reduced amount of corn starch in the formulation which was partially substituted with CCP. Due to the higher non-starch constituents in CCP such as insoluble fibre and minerals, the incorporation of more CCP to the formulation decreased the values of viscosity. Partial substitution of the corn starch with CCP delayed the swelling of the granules. Therefore, the product had low solubility and which in turn resulting in lower viscosity. The viscosity reduction of the beverage after the introduction of fibre sources into the formulation was also reported in two previous studies (Djoko et al., 1987; Chantaro et al., 2008). Besides, the lesser amount of corn starch in ICB30 also reduced the amount of water absorbed by starch and this, in turn, reduced the degree of gelatinization. Gelatinization is the modification of raw starch to a cooked and digestible material by applying heat and water. Water is absorbed and attached to the starch molecules and resulting in the changes of starch granule structure. In case of CCP content which had rich non-starch constituents such as insoluble fibre, the effect was similar to rice bran and mulberry leaves (Djoko et al., 1987; Chantaro et al., 2008) to obtain increased water binding capacity. Subsequently, the availability of water for gelatinization of the starch granule was reduced and resulting in less viscous ICBs. These results of viscosity analysis had suggested that it was possible to partially substitute some of the corn 
starch with $\mathrm{CCP}$ and at the same time maintain an optimum viscosity of the beverage.

Table 2. Viscosity (mpa.s) of different batches of instant cereal beverage at shear rates ranging from 100-1500 s

\begin{tabular}{lccc}
\hline & \multicolumn{3}{c}{ Viscosity (mpa.s) } \\
\hline Shear rate $\left(\mathrm{s}^{-1}\right)$ & 100 & 1000 & 1500 \\
\hline ICB10 & $274.27 \pm 0.06^{\mathrm{a}}$ & $65.17 \pm 0.12^{\mathrm{a}}$ & $50.87 \pm 0.06^{\mathrm{a}}$ \\
ICB20 & $144.70 \pm 0.10^{\mathrm{b}}$ & $17.77 \pm 0.06^{\mathrm{c}}$ & $15.73 \pm 0.06^{\mathrm{c}}$ \\
ICB30 & $50.07 \pm 0.06^{\mathrm{c}}$ & $12.37 \pm 0.06^{\mathrm{d}}$ & $8.73 \pm 0.06^{\mathrm{d}}$ \\
NGM & $45.63 \pm 0.06^{\mathrm{d}}$ & $18.63 \pm 0.06^{\mathrm{b}}$ & $16.43 \pm 0.06^{\mathrm{b}}$ \\
\hline
\end{tabular}

ICB10: instant cereal beverage powder substituted with $10 \%$ corncob powder, ICB20: instant cereal beverage powder substituted with $20 \%$ corncob powder, ICB30: instant cereal beverage powder substituted with $30 \%$ corncob powder, NGM: Nestum Grains and More 3 in 1. Data shown are mean value of triplicate \pm standard deviation. Values in the same column with various superscripts are statistically significant $(\mathrm{p}<0.05)$

\subsection{Colour measurements}

To understand the effect of CCP colour of various batches of ICBs, the values of $\mathrm{L}^{*}, \mathrm{a}^{*}$, and $\mathrm{b}^{*}$ of ICB were also determined and tabulated in Table 3. ICB30 had significantly $(p<0.05)$ the lowest values of $L^{*}(8.85)$ and $b^{*}(5.72)$ compared to ICB10 and ICB20. This result suggested that ICB tended to be browner with the increasing amount of CCP. The brownish colour of ICBs was contributed by the natural yellowish colour of corncob. The formulation of ICB10 and ICB20 with lesser substitution of corn starch with CCP had higher viscosity. The viscous consistency enabled CCP to be held within the suspension better and therefore resulting in a more uniform mixture with less CCP floating on top of the beverage compared to ICB30. Therefore, the ICB powder with a higher amount of CCP appeared to be more dark brown after the drum drying process of the mixture as more CCP was floating on the surface of the beverage. A study involving mulberry leaves in the formulation of ICB conducted by Chantaro et al. (2008) also showed that the lightness value $\left(\mathrm{L}^{*}\right)$ of the product decreased with the increased amount of mulberry leaves in the formulation of ICB. $\mathrm{L}^{*}$ and $\mathrm{b}^{*}$ values of ICB30 was significantly higher $(\mathrm{p}<0.05)$ than NGM which is its commercial counterparts. $L^{*}$ and $b^{*}$ values of NGM was recorded at 6.45 and 4.07, respectively. In terms of $a^{*}$ value, ICB10 had the lowest value (5.33) and less reddish in colour among all the sample tested due to its low content of CCP. Although all the 3 batches of ICBs had a significant difference $(\mathrm{p}<0.05)$ of $\mathrm{L}^{*}, \mathrm{a}^{*}$ and $\mathrm{b}^{*}$ values with NGM, colour appearance, and values of $\mathrm{L}^{*}$, $a^{*}$ and $b^{*}$ of ICB30 was found to be the closest to NGM. Therefore, colour appearance of ICB30 was the most appealing compared to ICB10 and ICB20.

\subsection{Sensory evaluation}

Although there was a large difference in the formulation of NGM and ICBs in this study, NGM was still chosen to be the counterpart because CCP incorporated ICB was quite new in the current market and so far, there was no product in the market was similar to ICBs in this study. Thus, NGM was the most related product in terms of food functionality, texture, taste, and main ingredients. Scores of the sensory evaluation of various ICBs and NGM was determined and tabulated in Table 4. In terms of colour, ICB30 had higher scores (6.80) than ICB20 (5.83) and significantly better $(p<0.05)$ than ICB10 (5.10) but its scores were insignificantly lower ( $p>0.05)$ than NGM (7.00). Due to the natural yellowish colour that was contributed by CCP, ICB30 appeared to be more palatable compared to ICB10 and ICB20. Besides contributing to the yellowish colour of ICB30, CCP also played an important role in providing good corn aroma to the beverage. Thus, scores of aroma for ICB30 (6.50) were significantly higher $(p<0.05)$ than ICB10 and ICB20. However, NGM insignificantly $(p>0.05)$ had better scores (7.57) than ICB30. All batches of ICB were insignificantly different ( $>0.05$ ) with each other in terms of scores for taste but significantly lower than NGM (7.17). This might be due to the presence of undisclosed ingredients that may serve as the company's trademark and the various grains in it which largely improved the taste, aroma, and colour as well. ICB10 had the lowest scores (2.73) in terms of viscosity due to the high amount of corn starch in the CF. The corn starch in it had caused ICB10 to be highly viscous and thus made the beverage to be less palatable. However, ICB30 had the best viscosity scores (7.13) compared to the other samples tested even though it did not have significant difference $(p>0.05)$ with NGM. Cereal beverage commonly will have certain gritty mouthfeel due to the presence of grains in it. ICB30 had significantly higher $(p<0.05)$ scores of grittiness $(5.97)$

Table 3. Colour parameters of different instant cereal beverages

\begin{tabular}{ccccc}
\hline Parameters & ICB10 & ICB20 & ICB30 & NGM \\
\hline $\mathrm{L}^{*}$ & $16.00 \pm 0.06^{\mathrm{a}}$ & $13.43 \pm 0.01^{\mathrm{b}}$ & $8.85 \pm 0.02^{\mathrm{c}}$ & $6.45 \pm 0.01^{\mathrm{d}}$ \\
$\mathrm{a}^{*}$ & $5.33 \pm 0.01^{\mathrm{d}}$ & $6.41 \pm 0.01^{\mathrm{c}}$ & $7.26 \pm 0.01^{\mathrm{a}}$ & $6.58 \pm 0.01^{\mathrm{b}}$ \\
$\mathrm{b}^{*}$ & $10.05 \pm 0.01^{\mathrm{a}}$ & $8.51 \pm 0.01^{\mathrm{b}}$ & $5.72 \pm 0.01^{\mathrm{c}}$ & $4.07 \pm 0.01^{\mathrm{d}}$ \\
\hline
\end{tabular}

ICB10: instant cereal beverage powder substituted with 10\% corncob powder, ICB20: instant cereal beverage powder substituted with $20 \%$ corncob powder, ICB30: instant cereal beverage powder substituted with $30 \%$ corncob powder, NGM: Nestum Grains and More 3 in 1. Data shown are mean value of triplicate \pm standard deviation. Values in the same column with various superscripts are statistically significant $(\mathrm{p}<0.05)$ 
Table 4. Sensory evaluation scores of various instant cereal beverages and its commercial counterparts, Nestum Grains and More 3 in 1.

\begin{tabular}{ccccc}
\hline Parameters & ICB10 & ICB20 & ICB30 & NGM \\
\hline Colour & $5.10 \pm 2.10^{\mathrm{b}}$ & $5.83 \pm 1.88^{\mathrm{ab}}$ & $6.80 \pm 1.16^{\mathrm{a}}$ & $7.00 \pm 1.68^{\mathrm{a}}$ \\
Aroma & $4.53 \pm 2.06^{\mathrm{b}}$ & $4.97 \pm 1.83^{\mathrm{b}}$ & $6.50 \pm 0.97^{\mathrm{a}}$ & $7.57 \pm 1.50^{\mathrm{a}}$ \\
Taste & $4.13 \pm 1.59^{\mathrm{b}}$ & $4.43 \pm 1.83^{\mathrm{b}}$ & $4.70 \pm 1.99^{\mathrm{b}}$ & $7.17 \pm 1.56^{\mathrm{a}}$ \\
Viscosity & $2.73 \pm 1.46^{\mathrm{bd}}$ & $4.37 \pm 1.96^{\mathrm{bc}}$ & $7.13 \pm 0.94^{\mathrm{a}}$ & $6.70 \pm 2.02^{\mathrm{a}}$ \\
Grittiness & $4.63 \pm 2.09^{\mathrm{b}}$ & $5.10 \pm 1.92^{\mathrm{bc}}$ & $5.97 \pm 1.52^{\mathrm{ac}}$ & $6.70 \pm 1.84^{\mathrm{a}}$ \\
Overall Acceptability & $3.83 \pm 1.49^{\mathrm{cd}}$ & $4.63 \pm 1.67^{\mathrm{cd}}$ & $6.00 \pm 1.39^{\mathrm{b}}$ & $7.37 \pm 1.65^{\mathrm{a}}$ \\
\hline
\end{tabular}

ICB10: instant cereal beverage powder substituted with $10 \%$ corncob powder, ICB20: instant cereal beverage powder substituted with $20 \%$ corncob powder, ICB30: instant cereal beverage powder substituted with $30 \%$ corncob powder, NGM: Nestum Grains and More 3 in 1. Data shown are mean value of triplicate \pm standard deviation. Values in the same column with various superscripts are statistically significant $(\mathrm{p}<0.05)$

than ICB10 and ICB20 and insignificantly $(p>0.05)$ lower than NGM. The grittiness of ICB30 was mainly contributed by the presence of CCP in the formulation. Although ICB30 was significantly $(p<0.05)$ less preferred by panelists compared to NGM, it was considered acceptable as its mean scores of overall acceptability (6.00) had exceeded 5.00. From the sensory evaluation of ICBs, formulation of ICB30 had the highest chance to be a potential product in the current instant cereal beverage market. This result also suggested that it was possible to incorporate high amounts of $\mathrm{CCP}$ into ICB while maintaining its palatability.

\section{Conclusion}

Corncob powder was successfully converted into high-value food product which were instant cereal beverage in this study. Besides, the relationship between their physicochemical and sensory properties with the amount of CCP in the formulations was studied as well. It was found that, by increasing the amount of $\mathrm{CCP}$, the viscosity of ICB could be reduced. With reduced viscosity, it was more favourable and preferred by consumers as in sensory evaluation, ICB with $30 \% \mathrm{CCP}$ had the highest scores in terms of viscosity. Although, ICB30 had lower scores in other aspects of sensory properties compared to the commercial counterpart (NGM) but, only taste and overall acceptability were significantly different $(\mathrm{p}<0.05)$. As in colour measurements, ICB30 was darker and more brownish than other formulations. It was found out that $\mathrm{L}^{*}$ and $\mathrm{b}^{*}$ values were inversely proportional to the amount of CCP in the formulation. However, the value of $\mathrm{a}^{*}$ was directly proportional to the amount of CCP. During the sensory evaluation, the colour of ICB30 had the highest scores and was significantly $(\mathrm{p}<0.05)$ different compared to the other two formulations as well. ICB which was incorporated with more than $30 \% \mathrm{CCP}$ was unable to be produced as the flakes failed to be produced from the drum drying process after the preliminary study was done. Thus, it was very crucial to use the suitable amount of CCP to be added into ICB formulation. From all the results obtained, it was concluded that there was a high chance for CCP to be applied in other food products in order to enhance their nutritional properties especially in terms of fibre content, as well as physicochemical and sensory properties.

\section{Conflict of interest}

The authors declare no conflict of interest.

\section{Acknowledgments}

We are grateful to the Department of Food Science, Faculty of Food Science and Technology (Universiti Putra Malaysia) for the equipment and technical support of this study.

\section{References}

Alfredo, V., Gabriel, R., Luis, C. and David, B. (2009). Physicochemical properties of a fibrous fraction from chia (Salvia hispanica L.). LWT-Food Science and Technology, 42(1), 168-173. https:// doi.org/10.1016/j.lwt.2008.05.012

Al-Okbi, S.Y., Hussein, A., Hamed, I.M., Mohamed, D.A. and Helal, A.M. (2014). Chemical, Rheological, Sensorial and Functional Properties of Gelatinized Corn-Rice Bran Flour Composite Corn Flakes and Tortilla Chips. Journal of Food Processing and Preservation, 38(1), 83-89. https:// doi.org/10.1111/j.1745-4549.2012.00747.x

AOAC. (2002). Official Methods of Analysis. $16^{\text {th }}$ ed. Washington: Association of Official Analytical Chemists.

Bookwalter, G., Conway, H. and Griffin, E. (1971). US Patent 3,579,352. United States of America: U.S. Patent and Trademark Office.

Charunuch, C., Tangkanakul, P., Limsangouan, N. and Sonted, V. (2008). Effects of extrusion conditions on the physical and functional properties of instant cereal beverage powders admixed with mulberry (Morus alba L.) leaves. Food Science and 
Technology Research, 14(5), 421-430. https:// doi.org/10.3136/fstr.14.421

Chia, S.L. and Chong, G.H. (2015). Effect of rotation speed and steam pressure on physico-chemical properties of drum dried pitaya (Hylocereus polyrhizus) peel. International Food Research Journal, 22(1), 372-376.

Ebihara, K. and Nakamoto, Y. (2001). Effect of the particle size of corn bran on the plasma cholesterol concentration, fecal output and cecal fermentation in rats. Nutrition Research, 21(12), 1509-1518. https:// doi.org/10.1016/S0271-5317(01)00380-3

Food and Agriculture Organization of the United Nations (FAO). (2016). Rome: FAO Statistics Division.

Guy, E. and Vettel, H. (1975). A High Quality Protein, Vitamin, and Mineral Fortified Chocolate-Flavored Powder for Beverage Use. Journal of Dairy Science, 58(3), 432-435. https://doi.org/10.3168/jds.S00220302(75)84585-1

Hasik, J., Dobrzańska, A. and Bartnikowska, E. (1997). Rola włókna roślinnego w żywieniu człowieka [The role of plant fiber in human nutrition]. SGGW, Warszawa, Poland.

Kuan, C., Yuen, K., Bhat, R. and Liong, M. (2011). Physicochemical characterization of alkali treated fractions from corncob and wheat straw and the production of nanofibres. Food Research International, 44(9), 2822-2829. https:// doi.org/10.1016/j.foodres.2011.06.023

Laurikainen, T., Härkönen, H., Autio, K. and Poutanen, K. (1998). Effects of enzymes in fibre-enriched baking. Journal of the Science of Food and Agriculture, 76(2), 239-249. https://doi.org/10.1002/ (SICI)1097-0010(199802)76:2<239::AIDJSFA942>3.0.CO;2-L

Naqvi, S., Ramessar, K., Farré, G., Sabalza, M., Miralpeix, B., Twyman, R.M., Capell, T., Zhu, C. and Christou, P. (2011). High-value products from transgenic maize. Biotechnology Advances, 29(1), 40 -53 . https://doi.org/10.1016/ j.biotechadv.2010.08.009

Ramessar, K., Sabalza, M., Capell, T. and Christou, P. (2008). Maize plants: an ideal production platform for effective and safe molecular pharming. Plant Science, 174(4), 409-419. https://doi.org/10.1016/ j.plantsci.2008.02.002

Rosell, C.M., Santos, E. and Collar, C. (2009). Physicochemical properties of commercial fibres from different sources: A comparative approach. Food Research International, 42(1), 176-184. https:// doi.org/10.1016/j.foodres.2008.10.003

Suter, P.M. (2005). Carbohydrates and dietary fiber.
Handbook of Experimental Pharmacology, 170, 231261. https://doi.org/10.1007/3-540-27661-0_8

Voca, N., Varga, B., Kricka, T., Curic, D., Jurisic, V. and Matin, A. (2009). Progress in ethanol production from corn kernel by applying cooking pre-treatment. Bioresource Technology, 100(10), 2712-2718. https://doi.org/10.1016/j.biortech.2008.12.030

Wong, N. (1993). Soil chemical characteristics of vegetable plots at Cameron Highlands. Malaysian Agricultural Research and Development Institute (MARDI) Report No. 170, p. 9. Selangor, Malaysia: MARDI 